\title{
The Lymphatic Drain of Below-Knee Malignant Melanoma: Is the Popliteal Fossa a Ghost Station?
}

\author{
Covarelli Piero ${ }^{1}$. Francesco Barberini ${ }^{1} \cdot$ Vincenzo De Giorgi ${ }^{2} \cdot$ Gabriele Anania $^{3} \cdot$ Alberto Santoro $^{4} \cdot$ Paolo Bruzzone $^{5}$. \\ Fabio Suadoni ${ }^{6}$. Carlo Boselli $^{1} \cdot$ Isaac Cheruiyot ${ }^{7} \cdot$ Barbara Palumbo $^{8} \cdot$ Roberto Cirocchi $^{1}$ (D)
}

Received: 28 July 2020 / Accepted: 28 January 2021 / Published online: 17 February 2021

(C) The Author(s) 2021

\begin{abstract}
Sentinel lymph node biopsy is fundamental in the staging of primary cutaneous melanoma (PCL), but reported lymphoscintigraphic patterns are very heterogeneous. In this systematic review, we evaluated the role of the popliteal station in below-knee PCL. A systematic search of literature through was conducted on the electronic databases PubMed, SCOPUS, and Web of Science (WOS) to identify eligible studies. A total of 22 studies ( $n=5673$ patients) were included. During the analysis of the included articles, it was not possible to classify patients into the 3 Menes popliteal drainage pattern, obtained by lymphoscintigraphy. The analysis of lymphatic drainage in patients undergoing lymphoscintigraphy for melanoma of the lower extremities below the knee was reported in 5637 patients and the type of lymphatic popliteal drainage was reported only in $5.64 \%$ (320 patients). The rate of popliteal lymph nodes melanoma metastases was $1.49 \%$ : they were located exclusively at the popliteal level in $0.60 \%$, at the popliteal and inguinal levels in $0.39 \%$, at the popliteal and iliac level in $0.02 \%$, and at the groin level in $0.48 \%$. In conclusion, the most common lymphoscintigraphic pattern is represented by popliteal nodes in-transit or interval nodes, so metastases from below-knee melanomas commonly transit through popliteal nodes stations and arrive to inguinal nodes stations. The popliteal nodes are the primary station in about $5.64 \%$ of cases. Larger studies are needed to corroborate these findings.
\end{abstract}

Keywords Primary cutaneous melanoma $\cdot$ Popliteal lymph nodes $\cdot$ Sentinel nodes

Francesco Barberini

francesco.barberini@unipg.it

Covarelli Piero

piero.covarelli@unipg.it

Vincenzo De Giorgi

vincenzo.degiorgi@unifi.it

Gabriele Anania

g.anania@unife.it

Paolo Bruzzone

paolo.bruzzone@uniroma1.it

Fabio Suadoni

fabio.suadoni@unipg.it

Carlo Boselli

carlo.boselli@unipg.it

Isaac Cheruiyot

isaacbmn@outlook.com

Barbara Palumbo

barbara.palumbo@unipg.it
Roberto Cirocchi

roberto.cirocchi@unipg.it

Department of General Surgery, University of Perugia, Perugia, Italy

2 Division of Dermatology, Department of Health Sciences, University of Florence, Florence, Italy

3 Department of Medical Science, Sant'Anna Hospital, University of Ferrara, Ferrara, Italy

4 Department of Surgical Sciences, La Sapienza University Hospital, Rome, Italy

5 Department of General Surgery, Surgical Specialties and Organ Transplantation "Paride Stefanini,", Sapienza University, Rome, Italy

6 Department of Legal Medicine, Hospital of Terni, Terni, Italy

7 Department of Human Anatomy, University of Nairobi, Nairobi, Kenya

8 Department of Surgical and Biomedical Sciences, University of Perugia, Perugia, Italy 


\section{Introduction}

Sentinel lymph node biopsy (SLNB) represents a fundamental step in the staging and prognosis of patients with primary cutaneous melanoma $(\mathrm{PCN})$ [1]. It is defined as the lymph node that first drains the lymph of a specific area of skin and is based on Halsted theory of stepwise dissemination of tumor cells from peritumoral lymphatics to the sentinel lymph node (SLN), and then to more distant lymph nodes. The candidates of SLNB are those with thick melanomas (Breslow thickness cut-off of $0.75 \mathrm{~mm}$ and $1 \mathrm{~mm}$ as per the National Comprehensive Cancer Network (NCCN) [2], and American Joint Committee on Cancer (AJCC) respectively) [3], or thinner melanoma in the presence of ulceration, high mitotic rate, and/or lymphovascular invasion [2]. The identification of these lymph nodes is performed via injection of tracers into the peritumoral site $[3,4]$. The current guidelines, according to the AJCC 8th edition [3] and the guidelines of the Italian Association of Medical Oncologists (AIOM) [5], changed the recommendation for SLN-positive cases. Although in the previous guidelines, these patients were managed with completion lymph node dissection (CLND), presently SLN positivity is not a mandatory indication for a CLND but lymph node dissection currently is indicated in macroscopic nodal disease (Stage IIIB+). Lymphatic drainage for most anatomical areas is variable, but it appears to be more predictable in the lower limbs (below-knee) [6], in which traditionally two main drainage routes are recognized:

- A major pathway, which originates from the medial edge of the foot and develops parallel to the great saphenous vein draining to the inguinal lymph nodes.

- A minor pathway, that originates from the lateral edge of the foot and runs along the small saphenous vein thus draining into the popliteal lymph nodes.

The introduction of the sentinel lymph node technique with lymphoscintigraphy has led to a better understanding of these drainage pathways of melanomas, challenging previous anatomical knowledge. For instance, Menes et al. reported 3 different patterns of drainage of melanoma of leg to the popliteal nodes as obtained by lymphoscintigraphic examination of patients with a SLN-positive biopsy [7] (Fig. 1a-c).

The aim of this systematic literature review is to evaluate the role of the popliteal basin in the lymphatic drain of belowknee melanoma and in SLNB.

\section{Methods}

\section{Study Guidelines, Protocol, and Registration}

This systematic review and meta-analysis was performed following the Cochrane Handbook for Systematic Reviews of
Fig. 1 a-c Patterns of drainage of melanoma of leg according to classification by Menes

Interventions guidelines [8], and reported as per the Preferred Reporting Items for Systematic Reviews and Meta-Analyses (PRISMA) guidelines [9].

\section{Search Strategy}

A thorough systematic search of literature through February 2020 was conducted by 2 independent reviewers (RC and FB) on the electronic databases PubMed, SCOPUS, and Web of Science (WOS) to identify studies eligible for inclusion using search strategies in Tables 1 and 2 below.

No language restriction was applied. Full texts of records remaining after initial screening by title and abstract were assessed to determine study eligibility. When the articles were published by the same study group and there was an overlap of the search period, only the most recent article was included to avoid duplication of data. The PubMed function "related articles" was used to extend the search and a reference list of all the included studies was analyzed. A search on Google Books was done for the analysis of the grey literature (https://books.google.com).

\section{Selection Criteria}

All titles and abstracts selected were evaluated by an initial double-blind screening by RC and FB. To be included in the review, a study had to report data about lymphoscintigraphy in patients with melanoma from the lower limbs below the level of the knee. Subsequently, the full texts of these selected articles were independently re-evaluated for suitability and inclusion in the systematic review. In cases of overlap between multiple articles published by the same researchers, only the most recent study was included to avoid double counting. Letter-to-editor, editorials, conference extracts, and studies with incomplete or irrelevant data were excluded.

\section{Data Extraction and Quality Assessment}

For each study, the following information was extracted by 2 independent reviewers (PC and RC) based on the model of the CHARMS Checklist (Critical Appraisal and Data Extraction for Systematic Reviews of Prediction Modelling Studies) (Supplement 1) [10]. Methodological quality of the included studies was assessed using the first eight entries of the Methodological Index for NonRandomized Studies (MINORS) tool [11]. The analysis was carried out in a double-blind fashion by $\mathrm{RC}$ and $\mathrm{CB}$. The items score were 0 (not shown); 1 (reported but inadequate); 2 (reported and adequate). The ideal global score is 16 for non-comparative studies. 
a
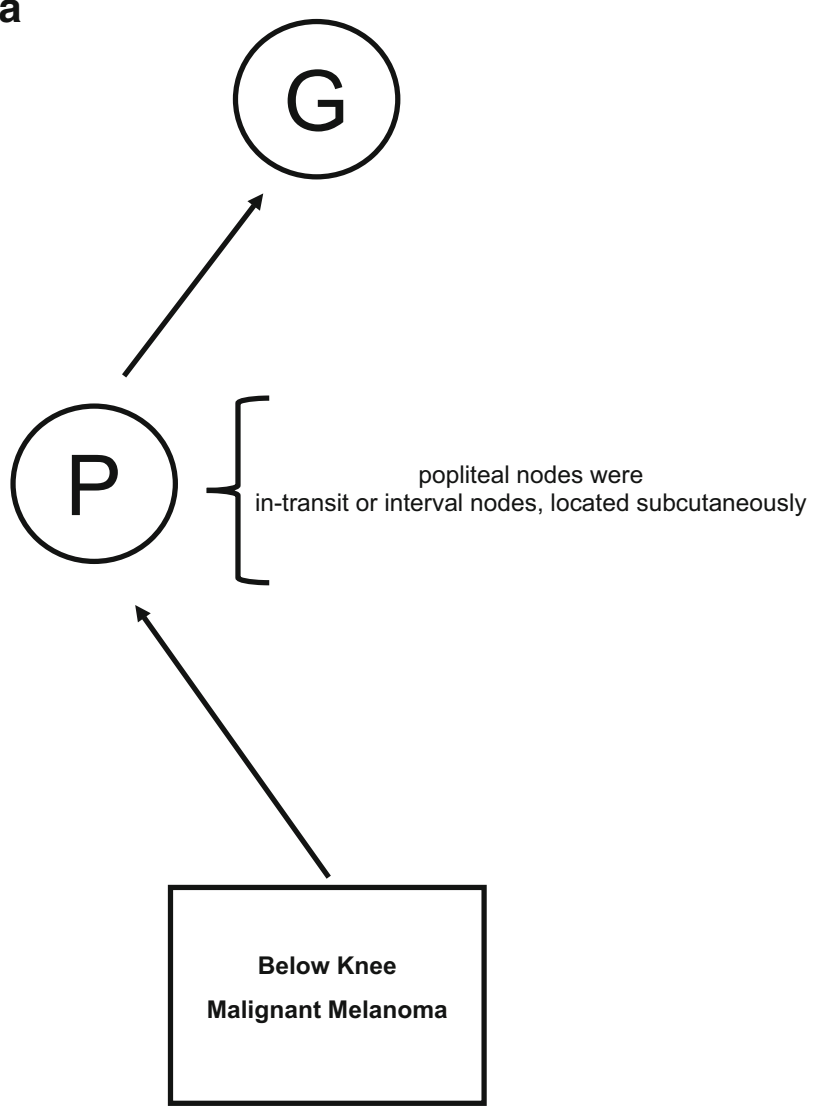

b

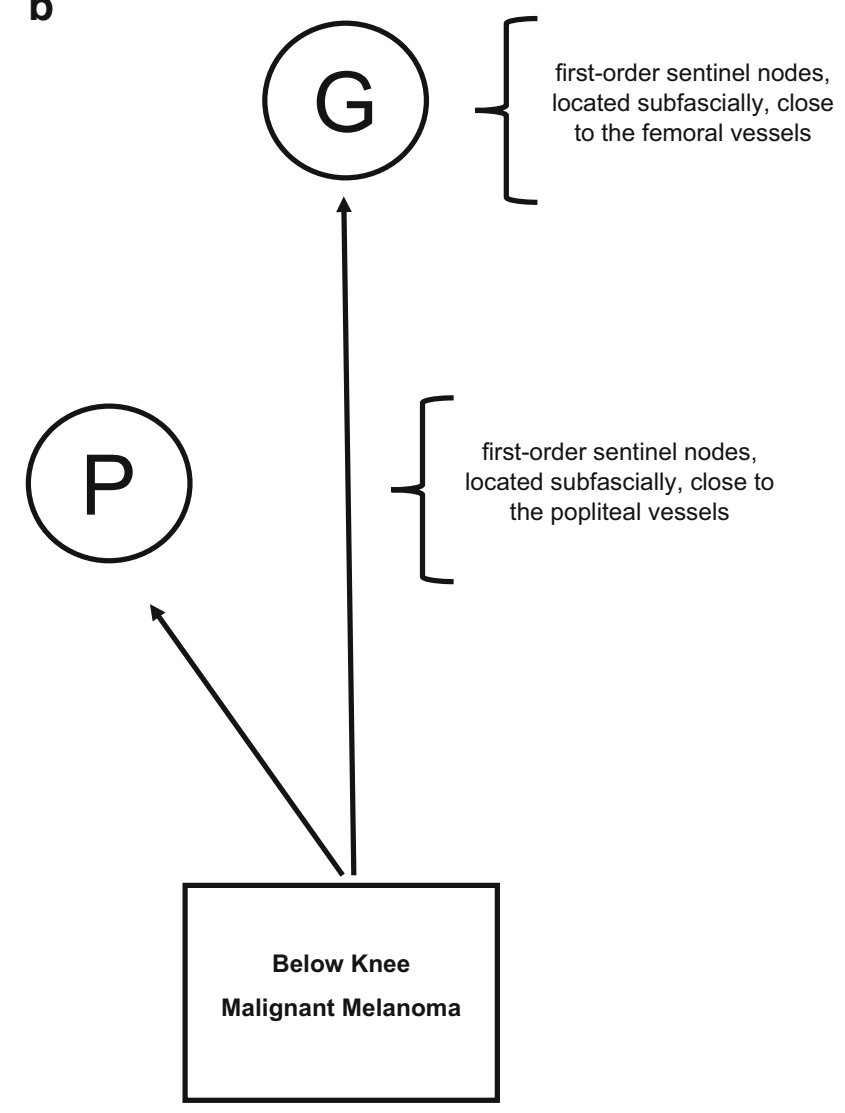

C

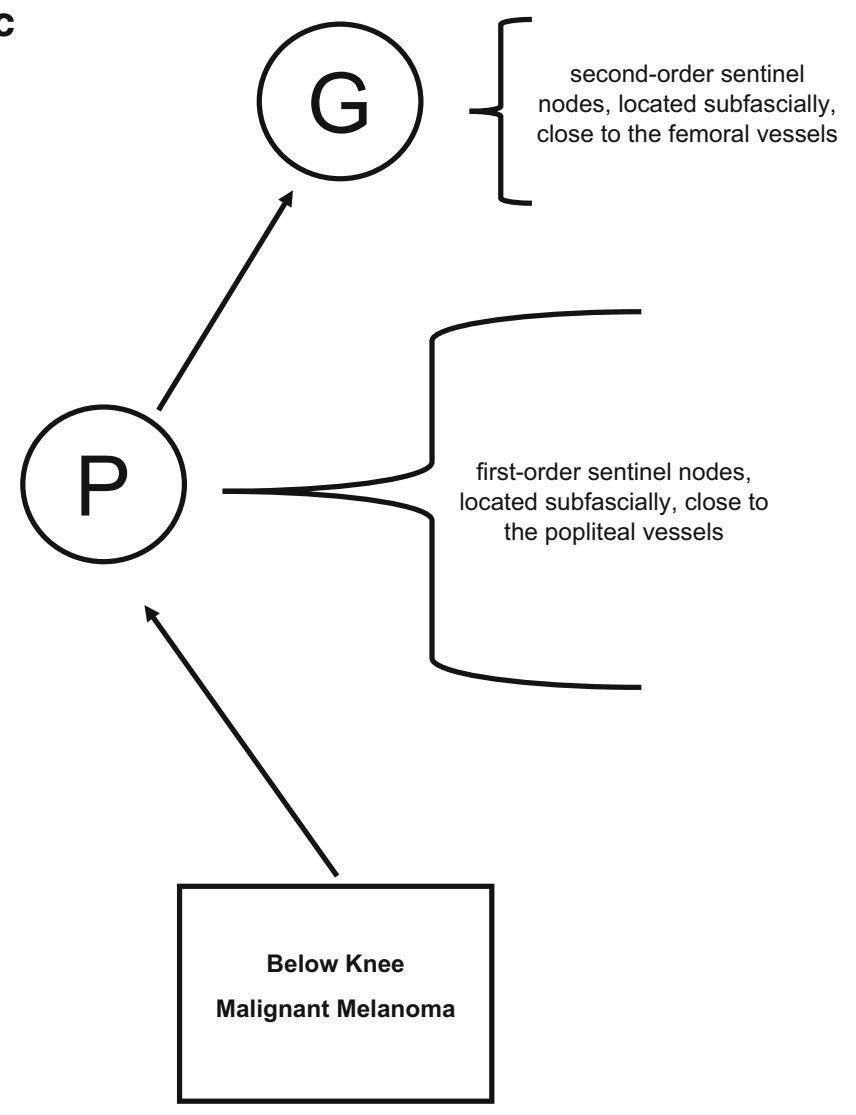


Table 1 Search strategy for PubMed

\begin{tabular}{ll}
1 & (popliteal[All Fields] AND fossa[All Fields]) AND (“melanoma”[MeSH Terms] \\
OR “melanoma”[All Fields]) \\
\hline $2 \quad$ (popliteal[All Fields] AND fossa[All Fields]) AND (“dissection”[MeSH Terms] \\
OR “dissection”[All Fields]) \\
(popliteal[All Fields] AND fossa[All Fields]) AND \\
("lymphoscintigraphy”[MeSH Terms] OR "lymphoscintigraphy"[All Fields])
\end{tabular}

\section{Study Outcomes}

The primary outcome was the type of popliteal node drainage in patients undergoing lymphoscintigraphy for melanoma of the lower limbs below the knee (as per the classification by Menes et al.) [7]. The secondary outcomes were the melanoma metastasis rate in patients with positive popliteal sentinel node, the type of popliteal lymphadenectomy, the type of surgical access technique at popliteal fossa, the overall survival (OS), and the disease-free survival (DFS).

\section{Meta-Analytical Synthesis Methods}

Due to the high heterogeneity displayed by the included studies, pooling of data was not performed. Instead, the results were summarized in a "summary of findings table" and a narration provided.

\section{Results}

The initial search yielded 348 potentially relevant articles. Following the removal of duplicates and primary screening, 25 articles were assessed by full text for eligibility in the metaanalysis. Of these, 3 were excluded because the primary and secondary outcomes of the study did not match that of this review (Supplement 2) [12-14]. Thus, a total of 22 articles were included in this systematic review (Fig. 2).

\section{Characteristics of the Included Studies and Quality Assessment}

A total of 22 studies ( $n=5673$ patients) were included from the literature [7, 15-35]. We have added to these articles another unpublished case report of a patient treated at our Surgical Unit of Melanoma Surgery (Table 3).

Table 2 Search strategy for SCOPUS and Web of Science

\begin{tabular}{ll}
\hline 1 & Popliteal AND fossa AND melanoma \\
\hline 2 & Popliteal AND fossa AND dissection \\
3 & Popliteal AND fossa AND lymphoscintigraphy \\
\hline
\end{tabular}

Majority of the studies were performed in Asia ( 9 studies, $n=221$ patients), followed from Europe ( 6 studies, $n=320$ patients) and the America (Brazil and USA) (6 studies, $n=1312$ patients). Only one study was from Oceania region (Australia, $n=3820$ patients).

The year of publication of the included studies ranged from 2002 to 2019. Most of the included patients were females $(54.8 \%)$. The average age of patients with positive popliteal involvement is 58 years. Rarely, melanomas can occur at a younger age, as described in a case report by Febrero et al. [18] in which the patient in question was 17-year-old. Similarly, in an observational study that Barrasa. et al. published in the Journal of the American College of Surgeons in 2011, one of the enrolled patients was 19-year-old [32]. However, considering all the cases, the incidence is higher around the 5th-6th decade. The greater number of cases of metastasis in the popliteal fossa around the 5th-6th decade is certainly due to a higher incidence of melanoma itself. The average Breslow thickness was $2.86 \mathrm{~mm}$.

The average score of the MINORS table, of the included studies was 11.27 (moderate risk) (Supplement 3).

\section{Primary Outcomes}

During the analysis of the included articles, it was not possible to classify patients into the 3 Menes popliteal drainage pattern, obtained by lymphoscintigraphy [7]:

- "prima via" (popliteal nodes as in-transit or interval nodes, located subcutaneously);

- "secunda via" (popliteal and inguinal nodes as both firstorder sentinel nodes, located subfascially, close to the popliteal and inguinal vessels);

- "tertia via" (popliteal nodes as first-order sentinel, located subfascially close to the popliteal vessels, and inguinal nodes as second-order sentinel, located subfascially close to the inguinal vessels).

In effect, most of the patients described in the included articles reviewed do not performed this classification. Furthermore, a lot of articles reported the presence of transit metastasis at popliteal station [7, 16, 26, 30,34], but it was possible perform an "ex post" analysis from articles if a popliteal node is subcutaneous or sub-fascial without reviewing imaging. 
Fig. 2 PRISMA flow diagram for the included studies
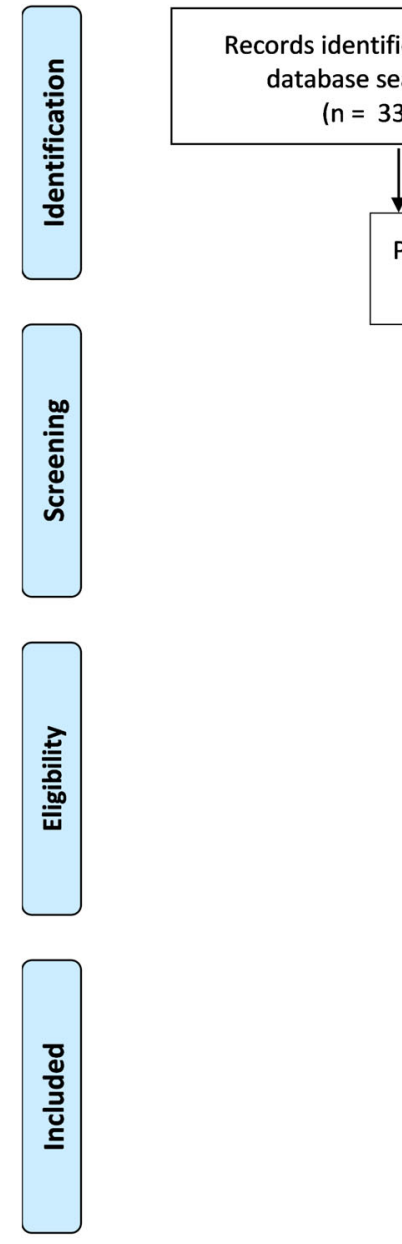

The analysis of lymphatic drainage in patients undergoing lymphoscintigraphy for melanoma of the lower extremities below the knee was reported in 5,637 patients and the lymphatic popliteal drainage was reported only in 5.64\% (320 patients).

\section{Secondary Outcomes}

The rate of popliteal lymph node melanoma metastasis was $1.49 \%$ (84 patients). Lymph node metastasis was located exclusively at the popliteal level in $0.60 \%$ (34 patients), at the popliteal and inguinal levels in $0.39 \%$ (22 patients), at the popliteal, and iliac level in $0.02 \%$ (1 patient) and at the inguinal level in $0.48 \%$ (27 patients) (Fig. 3).

In patients with popliteal sentinel node, the rate of CLND (complete lymph node dissection) was $13.43 \%$ (43/320 patients with popliteal drainage). Exclusively popliteal CLND rate was $60.47 \%$ (26 patients), while popliteal and inguinal CLND rate was $37.21 \%$ (16 patients), and the popliteal and iliac CLND rate was $2.326 \%$ (1 patient).

In all studies, the authors used the surgical access technique described by Karakousis by the Z plasty or S-shape technique. During lymphadenectomy, the average number of lymph nodes removed was 3.9. In 41 patients, the mean follow-up at 39 months was reported and the loss of patients at follow-up was $4.7 \%$ (2 patients); the OS was $70.7 \%$ (29 patients) and the DFS was $31.7 \%$ (13 patients).

\section{Discussion}

Metastasis of melanoma to popliteal nodes is a rare pathological condition. The lymphatic drainage of melanomas to the popliteal fossa is uncommon and few cases have been described in the literature [36]. For these reasons, some physicians do not perform the examination of the popliteal region during clinical examination and during lymphoscintigraphy in patients with melanoma of the leg [36]. In contrast, popliteal lymph nodes are the first station for the lymphatic drain of squamous carcinomas and sarcomas below the knee [37-39].

The classic Human Anatomy textbooks describe the popliteal lymph nodes as fundamental passage station in the lymphatic drainage of the leg and foot [40]. These nodes are located in the adipose tissue of the popliteal fossa (Fig. 4) near the popliteal vessels (Fig. 5) [41-43]. 
Table 3 Characteristics of the included studies

\begin{tabular}{|c|c|c|c|c|c|}
\hline $\begin{array}{l}\text { Author, year of } \\
\text { publication }\end{array}$ & Country & $\begin{array}{l}\text { Time of } \\
\text { enrollment }\end{array}$ & Type of analysis study & $\begin{array}{l}\text { Number of } \\
\text { patients enrolled }\end{array}$ & Age (median) \\
\hline Bertolli 2015 & Brazil & $2000-2010$ & Retrospective observational study & $247(100 \%)$ & 53 \\
\hline Costa 2008 & Brazil & 2008 & Case report & $1(100 \%)$ & 65 \\
\hline Covarelli 2013 & Italy & 2013 & Case report & $1(100 \%)$ & NR \\
\hline Febrero 2018 & Spain & 2018 & Case report & $1(100 \%)$ & 17 \\
\hline Georgeu 2002 & U.K. & 2002 & Case report & $1(100 \%)$ & 59 \\
\hline Ishihara 2005 & Japan & 2005 & Case report & $1(100 \%)$ & 43 \\
\hline Kaku 2012 & Japan & 2012 & Case report & $1(100 \%)$ & 69 \\
\hline Karadag 2017 & Turkey & 2017 & Case report & $1(100 \%)$ & 60 \\
\hline Kim HY 2009 & South Korea & 2009 & Case report & $2(100 \%)$ & 60 \\
\hline Kim 2017 & South Korea & $2006-2015$ & Retrospective observational study & $107(100 \%)$ & 60 \\
\hline Kretschmer 2011 & Germany & $1998-2010$ & Retrospective observational study & $166(100 \%)$ & NR \\
\hline Pandey 2016 & India & 2016 & Case report & $1(100 \%)$ & 35 \\
\hline Marone 2007 & Italy & $1996-2005$ & Retrospective observational study & $149(100 \%)$ & NR \\
\hline McGregor 2018 & USA & $1992-2012$ & Retrospective observational study & $246(100 \%)$ & NR \\
\hline Menes 2004 & Israel & $1993-2003$ & Retrospective observational study & $106(100 \%)$ & 55 \\
\hline Parrett 2016 & USA & 1995-2010 & Retrospective observational study & $356(100 \%)$ & 56 \\
\hline Nijhuis 2019 & Australia & 1992-2013 & Prospective observational study & $3820(100 \%)$ & 59 \\
\hline Sholar 2005 & USA & 2004 & Case report & $1(100 \%)$ & 52 \\
\hline Barrasa 2006 & Spain & 2014-2016 & Case report & $1(100 \%)$ & 68 \\
\hline Soydan 2008 & Turkey & 2006 & Case report & $1(100 \%)$ & 50 \\
\hline Steen 2011 & USA & $1971-2010$ & Retrospective observational study & $461(100 \%)$ & 55 \\
\hline Tanaka 2013 & Japan & 2013 & Case report & $1(100 \%)$ & 72 \\
\hline Total & & $1971-2018$ & & $5673(100 \%)$ & 58.1 \\
\hline
\end{tabular}

This is the first systematic review of the literature in which the role of popliteal lymph nodes in lymphatic drainage of the leg and foot in patients with melanoma has been assessed. The current review documents that melanoma of distal legs (below the knee) is more frequently observed in patients in the fifth or sixth decade of life, with a higher incidence in women and it is associated with a higher Breslow thickness (average 2.86 $\mathrm{mm}$ ). From the analysis of lymphoscintigraphy of the lower limbs performed for melanoma located below the knee, results different from those reported in the classic scientific literature emerge. These different types of lymphatic drainage were originally classified by Menes et al. [7] into 3 different patterns as obtained by lymphoscintigraphy in patients with a sentinel node-positive biopsy. This systematic review of the literature evaluated the role of the popliteal lymph nodes with respect to the different lymphoscintigraphic patterns of the leg and foot.

\section{Lymphatic Drainage of SNL}

The popliteal lymphatic drainage in patients undergoing lymphoscintigraphy for melanoma of the lower extremities below the knee was reported only in few cases (5.64\%).
In these patients, the classification of Menes represents a promising potential challenge that should be better investigated, but it is not clearly validated, according to the too small number of patients having described this popliteal drainage pattern, as presented by Menes [7]. In our systematic review, it was not possible to rank patients into the 3 Menes drainage pattern classification without reviewing the lymphoscintigraphic images of each patient.

In SLN, the most common lymphoscintigraphic pattern ("prima via") was represented by popliteal nodes in-transit

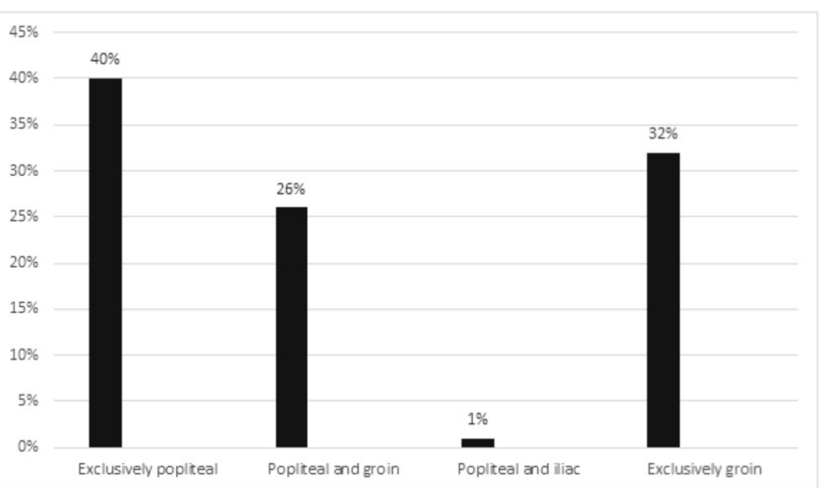

Fig. 3 Rate of popliteal lymph node melanoma metastasis in patients with lymphatic popliteal drainage 


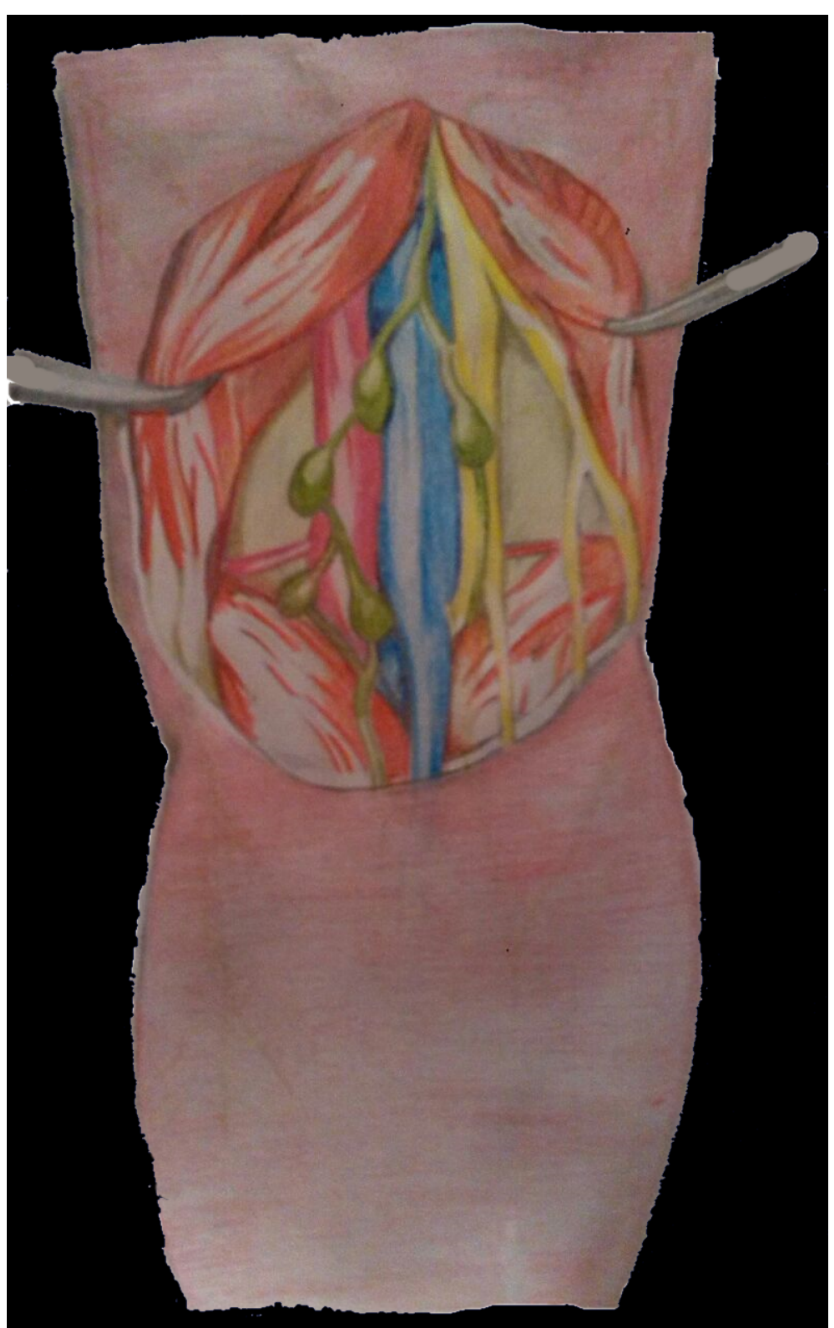

Fig. 4 Relationship between popliteal nodes and vessels in popliteal fossa

or interval nodes (Menes pattern 1) [7]. In this common type $[7,16,26,30,34]$, small lymph nodes were located at the subcutaneously level and represented only a passageway for lymphatics from the leg and directed to the groin. So, the metastasis from Melanoma, located at lower limb under the knee, commonly skip popliteal nodes station and arrive at to inguinal nodes station. Less commonly ("secunda via") [7],

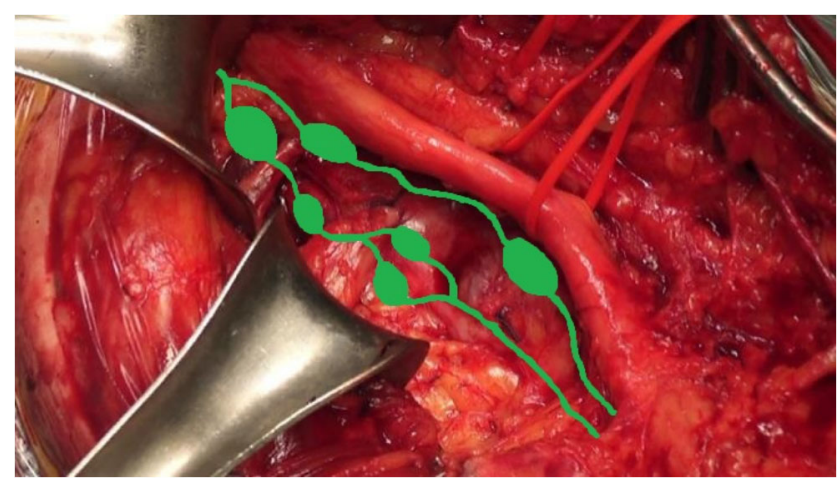

Fig. 5 Intraoperative dissection of popliteal fossa showing relationship between popliteal nodes and vessels lymphatic flow directs simultaneously through two distinct ways from the leg along the lymphatics located near the great saphenous vein to the inguinal lymph nodes and along lymphatics located near to of the small saphenous vein to the popliteal lymph nodes (Menes pattern 2).

In very rare situations ("tertia via") [7], the efferent path of the lymphatics coming from the leg reaches the subfascial popliteal lymph nodes, and from here, it continues toward the femoral vessels, draining into the deep inguinal lymphatic tissue (Menes pattern 3): popliteal nodes as first-order sentinel, located in the popliteal fossa subfascially close to the popliteal vessels, and inguinal nodes as second-order sentinel, located the popliteal fossa subfascially close to the inguinal vessels.

\section{Proposed Practice Guideline Based on the Menes Pattern for Popliteal Node Dissection}

In the "Menes pattern 1," the popliteal basin is jumped and a popliteal lymphadenectomy traditionally is not needed.

In patients with "Menes pattern 2," the simultaneous SLN+ positive at inguinal and popliteal station represents a dilemma for the surgeons and oncologists concerning the choice of performing popliteal lymphadenectomy or no not. In the past, there was an agreement between surgeons and oncologists to perform a step-up approach: first the popliteal lymphadenectomy, and successively the groin lymphadenectomy. The most common complication of this type of sequential popliteal/ inguinal lymphadenectomy was the severe lymphedema of the leg. For this reason, in new recommendations from international guidelines, completion lymphadenectomy is no longer the exclusive option in these cases. Lymphadenectomy is only reserved for patients in which clinical lymphadenopathy is encountered during the follow-up.

The Menes pattern 3 is still associated with clinical controversies consequent to the changes reported in the new international guidelines; therefore, new large studies are needed for analyze this small number of patients.

\section{Popliteal Lymph Node Dissection}

In this systematic review, only few patients underwent popliteal lymphadenectomy (13.43\%); the exclusively popliteal CLND rate was higher $(60.47 \%, 26$ patients) than the associated popliteal/inguinal CLND rate $(37.21 \%, 16$ patients); the rate of popliteal/iliac CLND (2.33\%, 1 patient) was lower. In these cases, the average number of popliteal lymph nodes removed was 3.9. It was not the aim of this systematic review to evaluate the improvement of patient survival possibly related to CLND: this issue has been addressed by many papers and some clinical trials [44]. In these patients with popliteal metastasis from malignant melanoma, the prognosis was very poor. Only $37 \%$ of patients who underwent CLND had no evidence of recurrent cancer after an average follow-up of 
39 months; in fact, $30 \%$ of the cases were still alive with melanoma recurrence and $28 \%$ of the cases died from recurrence. New imaging techniques such as photoacoustic ultrasound imaging could improve detection of lymph node micrometastasis [45].

\section{Conclusions}

The most common lymphoscintigraphic pattern is represented by popliteal nodes in-transit or interval nodes, so metastases from below-knee melanomas commonly transit through popliteal nodes stations and arrive to inguinal nodes stations. The popliteal nodes are the primary station in about $5.64 \%$ of cases. Larger studies are needed to corroborate these findings.

Supplementary Information The online version contains supplementary material available at https://doi.org/10.1007/s12262-021-02772-8.

Author Contribution PC and RC designed the project. FB wrote the manuscript with the contribution of GA, AS, and VDG. PB and CB proofread the text and revised the manuscript and provided funding. RC and VDG supervised the project. All authors discussed the results and contributed to the final manuscript. All authors have read and agreed to the published version of the manuscript.

Funding Open access funding provided by Università degli Studi di Perugia within the CRUI-CARE Agreement.

\section{Declarations}

Competing Interests The authors declare no competing interests.

Open Access This article is licensed under a Creative Commons Attribution 4.0 International License, which permits use, sharing, adaptation, distribution and reproduction in any medium or format, as long as you give appropriate credit to the original author(s) and the source, provide a link to the Creative Commons licence, and indicate if changes were made. The images or other third party material in this article are included in the article's Creative Commons licence, unless indicated otherwise in a credit line to the material. If material is not included in the article's Creative Commons licence and your intended use is not permitted by statutory regulation or exceeds the permitted use, you will need to obtain permission directly from the copyright holder. To view a copy of this licence, visit http://creativecommons.org/licenses/by/4.0/.

\section{References}

1. Rapport F, Smith AL, Cust AE, Mann GJ, Watts CG, Gyorki DE, Henderson M, Hong AM, Kelly JW, Long GV, Mar VJ, Morton RL, Saw RPM, Scolyer RA, Spillane AJ, Thompson JF, Braithwaite J (2020) Identifying challenges to implementation of clinical practice guidelines for sentinel lymph node biopsy in patients with melanoma in Australia: protocol paper for a mixed methods study. BMJ Open. 10(2):e032636

2. Ferrara G, Partenzi A, Filosa A (2018) Sentinel node biopsy in melanoma: a short update. Dermatopathology. 5(1):21-25
3. Gershenwald JE, Scolyer RA (2018) Melanoma staging: American Joint Committee on Cancer (AJCC) 8th edition and beyond. Ann Surg Oncol. 25(8):2105-2110

4. Thomas JM (2008) Sentinel lymph node biopsy in malignant melanoma. BMJ. 336(7650):902-903

5. Associazione Italiana di Oncologia Medica (AIOM). Linee Guida Melanoma. 2019. Accessed October 5, 2020. https://www.aiom.it/ wpcontent/uploads/2019/10/2019 LG AIOM Melanoma.pdf

6. Uren R, Thompson J, Howman-Giles R, Chung D (2006) Lymphatic drainage in patients with primary cutaneous melanoma - the role of lymphoscintigraphy in sentinel lymph node biopsy. Curr Med Imaging Rev. 2(2):261-270

7. Menes TS (2004) Lymphatic drainage to the popliteal basin in distal lower extremity malignant melanoma. Arch Surg. 139(9):10021006

8. Higgins, Green. Cochrane handbook for systematic reviews of interventions (internet). (cited 2020 Nov 5). Available from: https:// handbook-5-1.cochrane.org/

9. Moher D, Liberati A, Tetzlaff J, Altman DG (2009) PRISMA Group. Preferred reporting items for systematic reviews and meta-analyses: the PRISMA statement. Ann Intern Med. 151(4):264-269 W64

10. Moons KGM, de Groot JAH, Bouwmeester W, Vergouwe Y, Mallett S, Altman DG, Reitsma JB, Collins GS (2014) Critical appraisal and data extraction for systematic reviews of prediction modelling studies: the CHARMS checklist. PLOS Med. 11(10):e1001744

11. Slim K, Nini E, Forestier D, Kwiatkowski F, Panis Y, Chipponi J (2003) Methodological index for non-randomized studies (MINORS): development and validation of a new instrument. ANZ J Surg. 73(9):712-716

12. Thompson JF, Hunt JA, Culjak G, Uren RF, Howman-Giles R, Harman CR (2000) Popliteal lymph node metastasis from primary cutaneous melanoma. Eur J Surg Oncol. 26(2):172-176

13. Teixeira F, Moutinho V, Akaishi E et al (2014) Popliteal lymph node dissection for metastases of cutaneous malignant melanoma. World J Surg Oncol. 12(1):1-5

14. Skarpas G (2017) Key Anatomical structures for safe popliteal node dissection-a rare case series. MOJ Orthop Rheumatol 7(5)

15. Bertolli E, Bevilacqua JLB, Molina AS, De Macedo MP, Pinto CAL, Duprat Neto JP (2015) Popliteal sentinel lymph node involvement in melanoma patients. J Surg Oncol. 112(2):179-182

16. Costa SR, Couto Horta SH, Cruz HA (2008) Popliteal lymphadenectomy for treating metastatic melanoma: case report. Sao Paulo Med J. 126(4):232-235

17. Covarelli P, Burini G, Barberini F, Caracappa D, Boselli C, Noya G, Castellani E, Rulli A (2013) The integrated role of ultrasonography in the diagnosis of soft tissue metastases from melanoma: preliminary report of a single-center experience and literature review. In Vivo. 27(6):827-833

18. Febrero B, Rodríguez JM, Piñero A, Ríos A, Parrilla P (2018) Management of sentinel node melanoma metastasis in the popliteal fossa. Cirugía Española. 96(10):661-662

19. Georgeu GA, El-Muttardi N, Mercer DM (2002) Malignant melanoma metastasis to the sentinel node in the popliteal fossa. Br J Plast Surg. 55(5):443-445

20. Tsuyoshi I, Matsushita S, Kaguchi A (2005) Popliteal lymph node dissection. Skin Cancer. 1:23-26

21. Kaku Y, Tanioka M, Tanizaki H, Miyachi Y (2012) Popliteal sentinel lymph node biopsy is important in malignant melanoma of the distal lower extremities: a case report of acral lentiginous melanoma with simultaneous inguinal and popliteal lymph node micrometastases. EJD. 22(1):153-156

22. Karadağ EÇ, Gündeșlioğlu A (2017) özlem, Inan I. Malignant melanoma with simultaneous inguinal and popliteal lymph node metastases: a rare case report. Turk Plast Rekonstruktif ve Estet Cerrahi Derg. 25(2):103-106 
23. Kim HY, Chang H, Minn KW (2009) Popliteal lymph node dissection in lower extremity malignant melanoma. J Korean Soc Plast Reconstr Surg 36:485-488

24. Kim JH, Son J, Seong JY, Hur N, Choe J-H, Kim JS (2017) Management of sentinel lymph nodes in lower extremity melanoma with dual-basin (inguinal and popliteal) drainage on lymphoscintigraphy. Korean J Clin Oncol. 13(2):126-130

25. Kretschmer L, Sahlmann CO, Bardzik P, Thoms KM, Bertsch HP, Meller J (2011) Die Fossa poplitea? eine Problemzone bei der Sentinel-Lymphonodektomie. J Ger Soc Dermatology. 9(2):123-128

26. Pandey JK, Pandya SJ (2016) Popliteal lymphadectomy for cutaneous malignant melanoma with synchronous in-transit, palpable popliteal and groin metastases - a case report. Global Journal For Research Analysis 5(4):323-325

27. Marone U, Caracò C, Chiofalo MG, Botti G, Mozzillo N (2007) Resection in the popliteal fossa for metastatic melanoma. World $\mathrm{J}$ Surg Oncol 5:8

28. McGregor A, Pavri SN, Kim S, Xu X, Narayan D (2018) Eliminating preoperative lymphoscintigraphy in extremity melanomas. Plast Reconstr Surg - Glob Open. 6(3):1-4

29. Parrett BM, Li RR, Ph D, Chang T, Fadaki N (2012) Selective sentinel lymph node dissection. Melanoma Res. 22(5):386-391

30. Nijhuis AAG (2019) de A O Santos Filho ID, Uren RF, Thompson JF, Nieweg OE. Clinical importance and surgical management of sentinel lymph nodes in the popliteal fossa of melanoma patients. Eur J Surg Oncol. 45(9):1706-1711

31. Sholar A, Martin RCG, McMasters KM (2005) Popliteal lymph node dissection. Ann Surg Oncol. 12(2):189-193

32. Barrasa Shaw A, Sancho Merle F, Fuster Diana C, Campos Máñez J, Vázquez AC (2006) Popliteal lymphadenectomy on sentinel lymph node melanoma metastasis. Clin Transl Oncol. 8(3):218-220

33. Soydan A, Kayali M, Turgut G, Özkaya O, Baş L (2008) Alt ekstremite malıgn melanom olgularında nadir görülen bir durum;popliteal fossa metastazı ve diseksiyonu;olgu sunumu. Turk Plast Surg. 16:3

34. Steen ST, Kargozaran H, Moran CJ, Shin-Sim M, Morton DL, Faries MB (2011) Management of popliteal sentinel nodes in melanoma. J Am Coll Surg. 213(1):180-187
35. Tanaka K, Mori H, Okazaki M, Nishizawa A, Yokozeki H (2013) Long-term treatment outcome after only popliteal lymph node dissection for nodal metastasis in malignant melanoma of the heel: the only "interval node" dissection can be an adequate surgical treatment. Case Rep Oncol Med. 259326

36. Xifara A, Skarpas G, Zarokosta M, Zoulamoglou M, Piperos T et al (2017) Key anatomical structures for safe popliteal node dissectiona rare case series. MOJ Orthop Rheumatol 7(5):00289

37. Wright S, Armeson K, Hill EG, Streck C, Leddy L, Cole D, Esnaola N, Camp ER (2012) The role of sentinel lymph node biopsy in select sarcoma patients: a meta-analysis. Am J Surg. 204(4):428-433

38. Lhote R, Lambert J, Lejeune J (2018) Sentinel lymph node biopsy in cutaneous squamous cell carcinoma series of 37 cases and systematic review of the literature. Acta Derm Venereol. 98(7):671-676

39. Morcos BB, Hashem S, Al-Ahmad F (2011) Popliteal lymph node dissection for metastatic squamous cell carcinoma: a case report of an uncommon procedure for an uncommon presentation. World $\mathrm{J}$ Surg Onc 9:130

40. Standring S (2015) The lymphatic system. The lymphatics of the lower extremity. Gray's Anatomy, The Anatomical Basis of Clinical Practice. 41st edition, New York, pp 1482-1486

41. Földi M, Strößenreuther R (2005) Treatment of the inguinal lymph nodes and their tributary regions. In: Foundations of Manual Lymph Drainage (Third Edition). Mosby, Philadelphia, pp 84-96

42. Surhone LM, Timpledon MT, Marseken SF (2010) Popliteal lymph nodes. Betascript Publishin. Mauritius:5-12

43. Karin E (2012) Popliteal lymph nodes dissection. In: Khatri VP (ed) Atlas of Advanced Operative Surgery. Elsevier Health Sciences, Philadelphia, pp 482-486

44. Falk Delgado A, Zommorodi S, Falk Delgado A (2019) Sentinel lymph node biopsy and complete lymph node dissection for melanoma. Curr Oncol Rep 21(6):54

45. Lee YJ, Jeong EJ, Song HW, Ahn CG, Noh HW, Sim JY, Song DH, Jeon MY, Lee S, Kim H, Zhang M, Kim BK (2017) Photoacoustic imaging probe for detecting lymph nodes and spreading of cancer at various depths. J Biomed Opt. 22(9):91513

Publisher's Note Springer Nature remains neutral with regard to jurisdictional claims in published maps and institutional affiliations. 